Thorax, 1980, 35, 773-780

\title{
Radiographic, scintigraphic, and gas-dilution estimates of individual lung and lobar volumes in man
}

\author{
R J PIERCE, D J BROWN, AND D M DENISON
}

\author{
From the Lung Function Unit, Brompton Hospital, London
}

ABSTRACT We describe a method of separately determining the volumes of the right and left lungs from conventional chest radiographs and of determining the volumes of individual lobes and pathological spaces, whenever their boundaries are visible radiologically or can be displayed scintigraphically - for example, during fibreoptic bronchoscopy. Scintigrams of individual lungs, lobes, and segments are obtained by deflecting a stream of air marked with ${ }^{81 \mathrm{~m}}$ krypton down the suction channel of the bronchoscope into the appropriate bronchus during inspiration, followed by a breath-hold during which the image is recorded with a gamma camera. Both radiographic and scintigraphic methods have been validated by comparison with argon dilution estimates of individual lung and lobar volumes also obtained at bronchoscopy, and results for the three methods in normal subjects are presented. Used in conjunction with bronchoscopic soluble gas uptake studies, these volume measurements permit precise estimation of effective perfusion, tissue and water volume, and gas transfer at lobar and segmental level. Individual lung and lobar volumes can be used to quantify lung and lobar collapse and compression, mediastinal shift, regional ventilation and gas trapping, and phrenic paresis.

We have recently reported a method for the measurement of total lung volume from chest radiographs based on an assessment of the crosssectional shape of the thoracic structures derived from anatomical and tomographic studies. ${ }^{1}$ In this paper we report the extension of the radiographic method to the measurement of individual lung and lobar volumes and its application to scintigraphic ventilation scans of the whole lung or of individual lobes obtained at bronchoscopy. The radiographic and scintigraphic volumes are compared with gas dilution estimates of lobar volume obtained at bronchoscopy. These provide an independent assessment of the accuracy of the methods. The volumes of lung cysts and solid lesions can also be measured provided that their outlines are sufficiently visible, and reasonable assumptions can be made about their crosssectional shape. These methods were developed for the determination of regional function in patients with focal lung diseases, such as bronchiectasis, and neoplastic or bullous disease, especially when surgery is contemplated. In such cases a knowledge of the function of the affected

Addres3 for reprint requests: Dr D.M Denison, Lung Function Unit, Brompton Hospital, Fulham Rcad, London SW3 64P. and other parts of the lungs is often helpful in the management of the patient.

\section{Methods}

The healthy subjects studied were medical and laboratory staff. All were asymptomatic and had no past history of respiratory disease. They had normal results for routine lung function tests which included spirometry and maximal flow volume loops, plethysmographic estimates of lung volumes and airways resistance, and carbon monoxide transfer measured by the singlebreath technique.

\section{CHEST RADIOGRAPHS}

The radiographs of 10 normal subjects, aged 2650 years, were selected for individual lung and lobar volume estimation from those of a larger series of normal subjects because the interlobar fissures were clearly identifiable in the lateral views. These were $10 \mathrm{ft}, 150 \mathrm{keV}$, PA, and left lateral radiographs taken in the erect posture. For the comparison of radiographic with scintigraphic and gas-dilution volumes, eight further normal subjects had AP and lateral radiographs taken at a distance of $6 \mathrm{ft}$ in the supine or up- 
right posture, corresponding to that in which they were bronchoscoped.

The radiographic method for the estimation of total lung volume and the outlines of the thoracic structures used are described in an earlier paper. ${ }^{1}$ A digitiser is used to generate a series of co-ordinates corresponding to the outlines of the chest, heart, spine, and diaphragm. These are analysed by a computer which is used to calculate the volume of each of these structures and to derive lung volume by subtracting the volumes of the non-lung structures from that of the ohest. Studies of the cross-sectional shape of the thoracic structures demonstrated that the heart, spinal, and subphrenic structures can be considered as ellipses based on their PA and lateral radiographic diameters whereas the whole chest has an average cross-sectional shape onethird of the way between that of the ellipse and the rectangle that encloses it. In this paper we describe how the method has been extended to permit measurement of individual lung and lobar volumes using the same shape information.

Individual lung volumes are determined by reflecting in turn the left and right halves of the PA radiographic image about a mediastinal axis. The outlines of double-left and double-right hemithoraces (fig 1) thus produced are considered with the lateral radiographic outlines using the same cross-sectional information as for the cal-
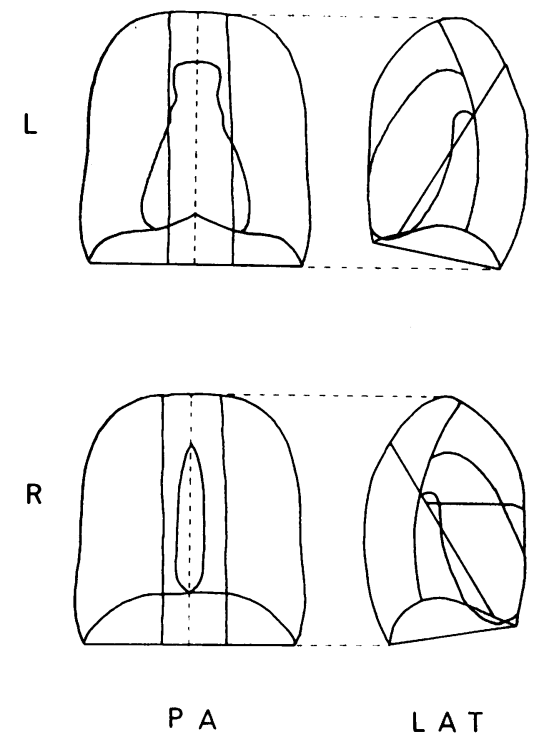

Fig 1 Outlines used in the radiographic estimation of individual lung and lobar volumes. culation of whole lung volume. The resulting volume estimates are those of a double-left and $\bar{c}$ double-right lung, and simply halving these gives $\vec{\phi}$ individual lung volume. The lateral outlines of $\varrho$ the whole of each thoracic structure are used $\$$ with that of the appropriate cupola of the dia- $\overrightarrow{0}$ phragm in the measurement of individual lung volume whereas only those parts within the boundaries of each lobe, determined by the inter- $\overrightarrow{2}$ lobar fissures, are used in the estimation of the $\vec{x}$ volume of individual lobes (fig 1). To estimate 0 lobar volumes the interlobar fissures must be $\vec{\circ}$ sufficiently discernible on the lateral radiograph. They are considered at any vertical level to lie $\omega$ in a plane perpendicular to the radiograph (fig 윽 2). This assumption is reasonable, since it is only when a substantial part of a fissure lies $\bigcirc$ directly in the line of the $\mathrm{x}$-ray beam that it is well seen on a radiograph. The left and right $\Phi$ major fissures are identified and distinguished in $\vec{P}$ the lateral radiograph by their junctions with $\otimes_{0}^{\circ}$ the appropriate hemidiaphragms and by the junction of the major and minor fissures in the right lung. When the entire length of a fissure is not seen completely, some extrapolation mayo be necessary especially at the upper ends of the major fissures.

The volumes of pathological spaces, such as $\vec{\circ}$ lung cysts and pneumothoraces, can also be 3 estimated. Cyst volumes are obtained by assuming them to have the same horizontal cross-? sectional area as ellipses generated by their PA and lateral radiographic diameters. The volume of a pneumothorax is calculated by assuming $x$ isotropic collapse of the affected lung so that its shape remains unaltered although volume is lost. The difference between the volumes of the col-o lapsed lung and the appropriate hemithorax is taken as that of the pneumothorax.

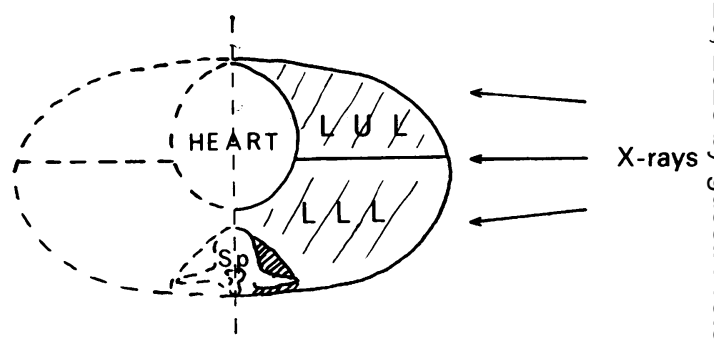

Fig 2 Diagramatic representation seen from below of a horizontal cross-section of the chest with the assumed anatomical orientation of the interlobar fissure to the $x$-ray beam in position for the lateral radiograph. 


\section{SCINTIGRAPIC STUDIES}

Lobar scintigrams were obtained at fibreoptic bronchoscopy by de.fecting a stream of ${ }^{81 \mathrm{~m}} \mathrm{krypton}$ eluted from a rubidium 81 generator, down the suction channel of the bronchoscope, as described by Williams et al. ${ }^{2}$ The bronchoscope directs the stream of radioactive gas into the lobe or lung under study while the subject performs a slow inspiration from residual volume to total lung capacity. The image is recorded with a low energy mobile gamma camera (Searle), during a breathhold at the end of the inspiration. The short half-life of ${ }^{81 \mathrm{~m}} \mathrm{krypton}$ ensures that the radioactivity in the lobe fades very rapidly so a sequence of anterior and lateral images can be obtained from each lobe in rapid succession.

The tube carrying the radioactive gas to the bronchoscope is taped to the chest wall over easily identified bony structures, usually the costal margin, sternum, and clavicle on the appropriate side. Radiation to these structures is reduced by placing a flexible strip of lead (a draughtsman's curve) between them and the tube of gas. The position of each lobe in relation to surface markings is thus established in the gamma camera images. Figure 3 shows the anterior scintigrams of the lobes of the left lung of a normal subject obtained in this way. Whole lung scans are also obtained in relation to these surface markings in the same body positions before and after bronchoscopy. The surface markings can then be used to locate the position of each lobe within the whole lung scan. In this way composite AP and lateral images of the lungs with the individual lobar boundaries within them are assembled.

The scintigraphic outlines are treated in the same way as the boundaries of the thoracic structures on radiographs to estimate the volumes of the whole and individual lungs and lobes using magnification factors appropriate for the gamma camera images. These are established by projecting the scans using an epidiascope to the same magnification as radiographs taken under known geometric conditions with the subject in the same posture as for the bronchoscopy. The outlines of the scans are drawn on paper at this magnification and are digitised in the same way as the radiographs. When overlap of adjacent lobar scans in the composite AP and lateral images occurred, the boundary was taken as midway between the adjacent edges. Magnification factors can also be established by

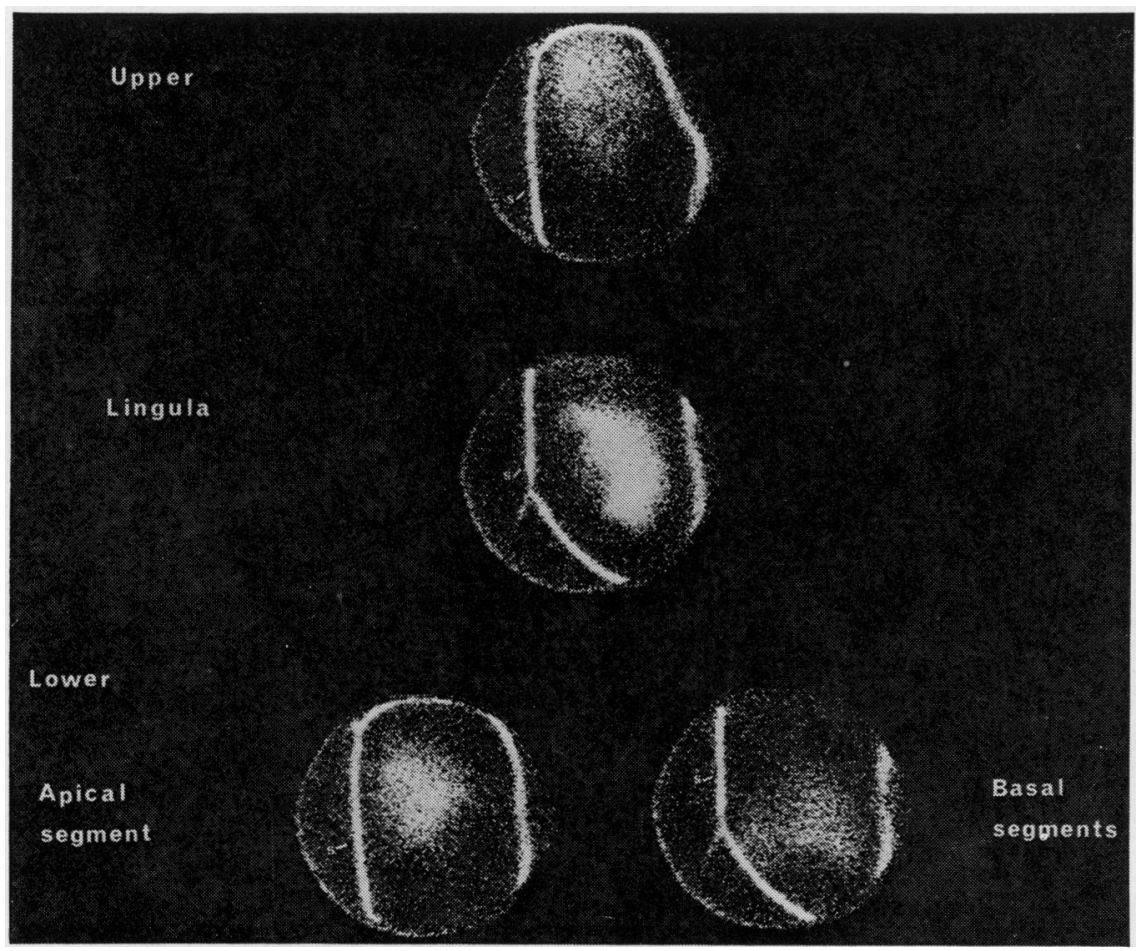

Fig 3 Lobar

$81 \mathrm{~m} k r y p t o n$ scans from a normal subject. The tubing which carries the krypton to the bronchoscope is taped to a draughtsman's curve over the costal margin, sternum, and clavicle to establish the surface anatomy of each lobe (reproduced by permission of $\mathrm{Br} \mathrm{J}$ Dis Chest). 
measuring scintigrams of containers, of known dimensions, filled with ${ }^{81 \mathrm{~m}}$ krypton and placed at measured distances using collimators of known angles. The crystal of the gamma camera used in these studies was large enough to scan whole lobes using a parallel-sided collimator, and hence the distance between the subject and the camera is less critical.

Figure 4 shows the anterior and lateral lobar scan images of the right lung of a normal subject together with their volumes derived by graphical analysis. These are expressed as a percentage of total lung volume. Lobar volumes calculated by this scintigraphic method were compared with those derived from radiographs taken in the same supine position in five normal subjects (aged 31-52 years). The lobes of the right lung were studied in two of the subjects, the lobes of the left lung in another two, and the lobes of both lungs were studied in the fifth. One subject was studied in the sitting posture $\stackrel{\mathbb{Q}}{\varrho}$ and all the others were supine during bronchoscopy.

BRONCHOSCOPIC INERT GAS DILUTION STUDIES

The principle of this method is the injection of a bolus of pure inert gas, in this case argon, $\vec{x}$ into a lobar bronchus during inspiration from $\mathbf{R V}$ w to TLC, and measurement of its concentration $\vec{\circ}$ in the subsequent lobar expirate via a mass? spectrometer sampling probe in the same bron- $\omega$ chus. This is done, as shown in fig 5 using a 음 modified Swan Ganz catheter (4 F) which has $\rightarrow$ been cut so that the orifice of the smaller lumen.

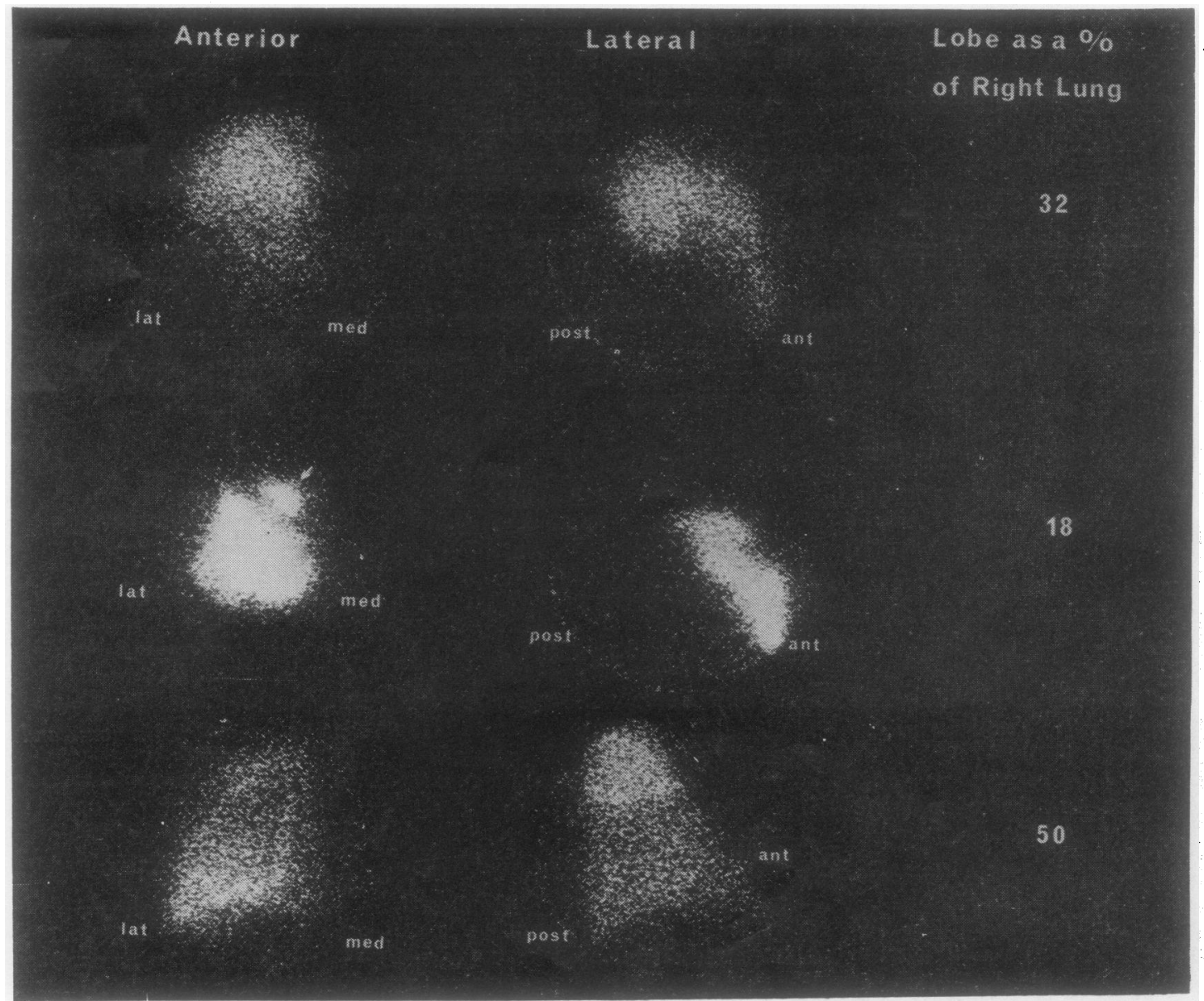

Fig 4 Anterior and lateral scintigrams of the lobes of the right lung of a normal subject with the estimated lobar volumes expressed as a \% of the whole right lung volume (reproducet by permission of $\mathrm{Br} \mathrm{J}$ Dis Chest). 


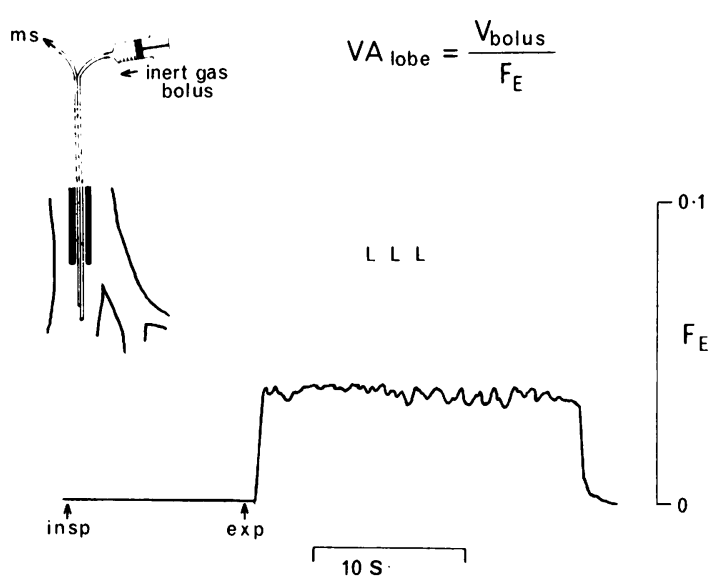

Fig 5 Diagramatic representation of method used for estimating lobar volumes by the inert gas dilution method. The bolus used in these studies was $50 \mathrm{ml}$ of pure argon. A typical tracing and the equation used in the calculation of lobar volume are shown.

which had previously served the inflatable balloon, is $1-2 \mathrm{~mm}$ proximal to the orifice of the larger distal lumen. The bolus of inert gas is delivered to the lobar bronchus through the large distal lumen by a steady injection over the second to the eighth seconds of a 10 second vital capacity inspiration. Gas is sampled continuously from the smaller proximal lumen by a mass spectrometer (TC Centronics Ltd). It is certain that the entire bolus has gone into the lobe without reflux if no argon is seen at the proximal lumen during the inspiration in which it is injected.

The concentration of the argon in the expirate is recorded either against time at a fixed expiratory rate or against expired volume on an $X Y$ recorder. The gas-dilution volume of the lobe at TLC is calculated from the expired fractional concentration, $\left(F_{E}\right)$, and the volume of the bolus of pure argon using the equation:

$$
\mathrm{VA} \text { lobe }=\mathrm{V} \text { bolus } / \mathrm{F}_{\mathrm{E}}
$$

A period of several minutes quiet breathing is allowed after each bolus to enable washout of the inert gas to occur before proceeding to the next lobe. The rate and completeness of this washout can be observed and recorded by continuous sampling from the bronchial tree. The washout was rapid and a period of three minutes was allowed between manoeuvres in the normal subjects studied. This enabled duplicate surveys of all of the lobes to be completed within the time course of a single bronchoscopy.
The procedure was performed on three normal male subjects (aged 23-35 years) in the supine position, and repeated on one of the subjects in the sitting position at a second bronchoscopy one week later to determine the effect of posture. PA and lateral chest radiographs were taken in the same positions and the radiographic lobar volumes of the same subjects measured for comparison with the gas-dilution estimates.

\section{Results}

The radiographic estimates of TLC and the percentage of TLC constituted by each individual lung and each lobe in the 10 normal subjects (routine chest radiographs) are shown with the group means and standard deviations in table 1 . Total lung capacity was measured separately and as the sums of firstly the two individual lung volumes and secondly the five lobar volumes in all subjects. The differences between the TLC estimates calculated by each of these three methods were never more than $100 \mathrm{ml}$ and are used as an internal check on the accuracy of each measurement. Lobar volumes are expressed as a percentage of the TLC derived from the sum of all lobes.

The results derived from lobar scintigrams are shown in table 2 as a percentage of individual lung volume and (in brackets) as a fraction of the corresponding percentage volume estimate from the radiographs of the same subject in the same posture. One subject (BS) had both lungs studied, making a series of three for each lung from the five subjects.

The argon dilution estimates of lobar volume, which were also obtained at bronchoscopy, are shown as percentage of TLC and as a fraction of the corresponding percentage radiographic estimate in table 3 . The four sets of results in this series are from three subjects, one of whom (CW) was studied in both sitting and supine postures.

The volumes of the upper division and lingular segments of the left upper lobe were estimated separately as well as together in the three subjects whose left lung was studied scintigraphically and in three of the four argon dilution studies. The left upper division constituted a mean of $58.4 \% \pm 3.0 \%$ of the left upper lobe in the scintigraphic estimates and $57 \cdot 3 \% \pm 3 \cdot 3 \%$ by the gasdilution method. The corresponding mean figures for the lingula were $41.6 \% \pm 3.0 \%$ by the scintigraphic and $42.7 \% \pm 3.3 \%$ by the gas-dilution methods. The absence of a visible minor fissure in the left lung precludes this measure- 
Table 1 Radiographic individual lung and lobar volume estimates $(\% T L C)$ in 10 normal subjects

\begin{tabular}{|c|c|c|c|c|c|c|c|c|}
\hline Subject & $\begin{array}{l}T L C \\
\text { (litres) }\end{array}$ & $R$ lung & $L$ lung & $R U L$ & $\begin{array}{l}R M L \\
(\%)\end{array}$ & $R L L$ & $L U L$ & $L L L$ \\
\hline $\begin{array}{l}\text { DC } \\
\text { SW } \\
\text { BS } \\
\text { RP } \\
\text { CT } \\
\text { PT } \\
\text { MS } \\
\text { MC } \\
\text { DD } \\
\text { JB }\end{array}$ & $\begin{array}{l}7 \cdot 87 \\
8 \cdot 52 \\
7.94 \\
7 \cdot 13 \\
8 \cdot 72 \\
4.63 \\
8.02 \\
6.41 \\
9.06 \\
8 \cdot 74\end{array}$ & $\begin{array}{l}52 \cdot 3 \\
52 \cdot 7 \\
51 \cdot 7 \\
52 \cdot 8 \\
52 \cdot 5 \\
51 \cdot 5 \\
52 \cdot 8 \\
52 \cdot 5 \\
51 \cdot 8 \\
54 \cdot 1\end{array}$ & $\begin{array}{l}47 \cdot 7 \\
47 \cdot 3 \\
48 \cdot 3 \\
47 \cdot 2 \\
47 \cdot 5 \\
48 \cdot 5 \\
47 \cdot 2 \\
47 \cdot 5 \\
48 \cdot 2 \\
45 \cdot 9\end{array}$ & $\begin{array}{l}14 \cdot 0 \\
16 \cdot 2 \\
20 \cdot 1 \\
13 \cdot 6 \\
15 \cdot 2 \\
18 \cdot 8 \\
17 \cdot 4 \\
16 \cdot 6 \\
15 \cdot 5 \\
17 \cdot 0\end{array}$ & $\begin{array}{r}8.9 \\
9.5 \\
6.9 \\
11.4 \\
10.2 \\
9.9 \\
10.0 \\
8.8 \\
8.2 \\
12.0\end{array}$ & $\begin{array}{l}29 \cdot 4 \\
27 \cdot 0 \\
24 \cdot 7 \\
27 \cdot 8 \\
27 \cdot 1 \\
22 \cdot 8 \\
25 \cdot 4 \\
27 \cdot 0 \\
28 \cdot 1 \\
25 \cdot 1\end{array}$ & $\begin{array}{l}20 \cdot 7 \\
26 \cdot 1 \\
25 \cdot 3 \\
22 \cdot 5 \\
24 \cdot 3 \\
26 \cdot 4 \\
24 \cdot 3 \\
22 \cdot 9 \\
23 \cdot 0 \\
24 \cdot 7\end{array}$ & $\begin{array}{l}27 \cdot 0 \\
21 \cdot 2 \\
23 \cdot 0 \\
24 \cdot 7 \\
23 \cdot 2 \\
22 \cdot 1 \\
22 \cdot 9 \\
24 \cdot 6 \\
25 \cdot 2 \\
21 \cdot 2\end{array}$ \\
\hline Mean & $7 \cdot 70$ & 52.5 & $47 \cdot 5$ & $16 \cdot 4$ & $9 \cdot 6$ & $26 \cdot 4$ & $24 \cdot 0$ & 23.5 \\
\hline SD & $1 \cdot 34$ & 0.74 & 0.74 & 2.02 & 1.49 & 1.93 & $1 \cdot 76$ & 1.86 \\
\hline
\end{tabular}

Table 2 Scintigraphic lobar volume estimates (\% of individual lung volume, fraction of radiographic $\%$ estimate) in five normal subjects

\begin{tabular}{llclll}
\hline Subject & $R U L$ & $R M L$ & $R L L$ & $L U L$ & $L L L$ \\
\hline BS & $32 \cdot 8(1.03)$ & $16 \cdot 2(1.05)$ & $50.4(0.96)$ & $48.6(1.06)$ & $51.4(0.95)$ \\
ND & $28.0(0.95)$ & $19 \cdot 8(0.92)$ & $52 \cdot 2(1.07)$ & - & - \\
RP & $28.8(0.96)$ & $17 \cdot 2(0.97)$ & $54.0(1.03)$ & - & - \\
NS & - & - & - & $43.0(1.03)$ & $57.0(0.98)$ \\
TS & - & - & - & $39 \cdot 1(0.92)$ & $60.9(1.06)$ \\
Mean & $29.9(0.98)$ & $17.9(0.98)$ & $52.2(1.02)$ & $43.6(1.00)$ & $56.4(1.00)$ \\
n=3 & & & & & \\
SD & $2.6(0.04)$ & $1.9(0.07)$ & $1.8(0.06)$ & $4.8(0.07)$ & $4.8(0.06)$
\end{tabular}

* This subject was studied in the upright posture.

Table 3 Argon dilution lobar volume estimates (\% TLC, fraction of radiographic $\%$ volume) in three normal subjects

\begin{tabular}{|c|c|c|c|c|c|c|c|}
\hline Subject & $R$ lung & $L$ lung & $R U L$ & $R M L$ & $R L L$ & $L U L$ & $L L L$ \\
\hline L & $\begin{array}{l}51 \cdot 3 \\
(1 \cdot 00)\end{array}$ & & & & $\begin{array}{l}22.7 \\
(0.85)\end{array}$ & $\begin{array}{l}27 \cdot 1 \\
(1 \cdot 00)\end{array}$ & $\begin{array}{l}21 \cdot 6 \\
(1.00)\end{array}$ \\
\hline sw & $\begin{array}{l}50 \cdot 3 \\
(0.95)\end{array}$ & $\begin{array}{l}49 \cdot 7 \\
(1.05)\end{array}$ & $\begin{array}{l}13.3 \\
(0.83)\end{array}$ & $\begin{array}{l}7.8 \\
(0.82)\end{array}$ & $\begin{array}{l}29.0 \\
(1.08)\end{array}$ & $\begin{array}{l}28.7 \\
(1.09)\end{array}$ & $\begin{array}{l}21.0 \\
(0.99)\end{array}$ \\
\hline $\mathrm{CW}$ & $\begin{array}{l}51.6 \\
(0.98)\end{array}$ & $\begin{array}{l}48 \cdot 8 \\
(1 \cdot 02)\end{array}$ & $\begin{array}{l}16.2 \\
(0.99)\end{array}$ & $\begin{array}{l}10.6 \\
(1.09)\end{array}$ & $\begin{array}{l}24.2 \\
(0.92)\end{array}$ & $\begin{array}{l}24.2 \\
(1.02)\end{array}$ & $\begin{array}{l}24 \cdot 2 \\
(1.02)\end{array}$ \\
\hline $\mathrm{CW}^{*}$ & $\begin{array}{l}50 \cdot 3 \\
(1.01)\end{array}$ & $\begin{array}{l}49 \cdot 7 \\
(1 \cdot 00)\end{array}$ & $\begin{array}{l}16.8 \\
(0.89)\end{array}$ & $\begin{array}{l}10.2 \\
(1.04)\end{array}$ & $\begin{array}{l}23 \cdot 0 \\
(1.07)\end{array}$ & $\begin{array}{l}28.2 \\
(1.01)\end{array}$ & $\begin{array}{l}21.5 \\
(1.00)\end{array}$ \\
\hline Mean & $\begin{array}{l}50.9 \\
(0.99)\end{array}$ & $\begin{array}{l}49 \cdot 1 \\
(1 \cdot 02)\end{array}$ & $\begin{array}{l}16 \cdot 1 \\
(1 \cdot 00)\end{array}$ & $\begin{array}{l}9 \cdot 7 \\
(0.99)\end{array}$ & $\begin{array}{l}24.7 \\
(0.98)\end{array}$ & $\begin{array}{l}27 \cdot 1 \\
(1 \cdot 03)\end{array}$ & $\begin{array}{l}22 \cdot 1 \\
(1 \cdot 00)\end{array}$ \\
\hline SD & $\begin{array}{l}0.7 \\
(0.03)\end{array}$ & $\begin{array}{l}0.7 \\
(0.02)\end{array}$ & $\begin{array}{l}2 \cdot 1 \\
(0 \cdot 20)\end{array}$ & $\begin{array}{l}1 \cdot 3 \\
(0 \cdot 12)\end{array}$ & $\begin{array}{l}2.9 \\
(0.11)\end{array}$ & $\begin{array}{l}2.0 \\
(0.04)\end{array}$ & $\begin{array}{l}1.4 \\
(0.01)\end{array}$ \\
\hline
\end{tabular}

* This study was performed in the sitting posture.

ment by the radiographic method.

Three subjects in this study (CW, RP, and BS) had radiographic lobar volumes measured in both supine and upright postures. In all three subjects the lower lobes were found to constitute a smaller proportion of TLC in the upright compared with the supine posture. The absolute
Table 4 Effect of posture on radiographic lung and lobar volumes (mean $\% T L C \pm 1 S D$ ) in three normal subjects

\begin{tabular}{|c|c|c|c|c|c|c|c|c|}
\hline Position & $\begin{array}{l}T L C \\
\text { (litres) }\end{array}$ & $R$ lung & $L$ lung & $R U L$ & $\begin{array}{r}R M L \\
(\%)\end{array}$ & $R L L$ & $L U L$ & $L L L$ \\
\hline Upright & $\begin{array}{l}8 \cdot 26 \\
(1 \cdot 30)\end{array}$ & $\begin{array}{l}51 \cdot 5 \\
(1 \cdot 3)\end{array}$ & $\begin{array}{l}48 \cdot 5 \\
(1 \cdot 1)\end{array}$ & $\begin{array}{l}17 \cdot 5 \\
(3 \cdot 5)\end{array}$ & $\begin{array}{l}9 \cdot 4 \\
(2 \cdot 3)\end{array}$ & $\begin{array}{l}24 \cdot 7 \\
(3 \cdot 2)\end{array}$ & $\begin{array}{l}25.4 \\
(2.9)\end{array}$ & $\begin{array}{l}23.0 \\
(1.7)-\end{array}$ \\
\hline Supine & $\begin{array}{l}8 \cdot 13 \\
(0.68)\end{array}$ & $\begin{array}{l}50 \cdot 9 \\
(1 \cdot 3)\end{array}$ & $\begin{array}{l}49 \cdot 1 \\
(1 \cdot 3)\end{array}$ & $\begin{array}{l}15 \cdot 8 \\
(0.7)\end{array}$ & $\begin{array}{l}8 \cdot 8 \\
(0 \cdot 8)\end{array}$ & $\begin{array}{l}26 \cdot 3 \\
(0 \cdot 2)\end{array}$ & $\begin{array}{l}22.9 \\
(0.9)\end{array}$ & $\begin{array}{l}26 \cdot 2 \omega \\
(2 \cdot 2)\end{array}$ \\
\hline
\end{tabular}

Table 5 Individual lung and lobar volumes: comparison of four methods

\begin{tabular}{|c|c|c|c|c|}
\hline & $\begin{array}{l}\text { Radiographic } \\
\text { method } \\
(n=10)\end{array}$ & $\begin{array}{l}\text { Bronchoscopic } \\
\text { scintigrams } \\
(n=5)\end{array}$ & $\begin{array}{l}\text { Inert gas- } \\
\text { dilution } \\
(n=4)\end{array}$ & $\begin{array}{l}\text { Anatomical } \\
\text { data } \\
\text { (Horsfield })\end{array}$ \\
\hline$R$ lung & 52.5 & - & 50.9 & 54.6 \\
\hline$L$ lung & $47 \cdot 5$ & - & $49 \cdot 1$ & $45 \cdot 5$ \\
\hline$R U L$ & 16.4 & $15 \cdot 7$ & $16 \cdot 1$ & 20.9 \\
\hline$R M L$ & $9 \cdot 6$ & $9 \cdot 4$ & $9 \cdot 7$ & 9.0 \\
\hline$R L L$ & $26 \cdot 4$ & $27 \cdot 4$ & $24 \cdot 7$ & 24.7 \\
\hline LUL & 24.0 & $20 \cdot 7$ & $27 \cdot 1$ & $20 \cdot 8$ \\
\hline$L L L$ & $23 \cdot 5$ & $26 \cdot 8$ & $22 \cdot 1$ & $24 \cdot 6$ \\
\hline
\end{tabular}

Scintigraphic volumes were converted from $\%$ individual lung volume to \% TLC using the left and right lung proportions of TLC found in the radiographic studies. Four of the scintigraphic and threक्रे argon diluiion studies were performed in the supine position.

TLC was slightly larger in the upright posture (mean difference $130 \mathrm{ml}$ ) and the reduction in lower lobe proportions was balanced by an in crease in the proportion of TLC constituted by the middle and upper lobes. The mean values for the two postures are shown in table 4 and the differences are probably the result of gravitaotional compression of the lower lobes in the upright posture by the weight of the middle an $\&$ upper lobes.

The mean values for lobar volume as percento age of TLC for the three methods describes in this paper are compared with the data of Horsfield $^{3}$ derived from anatomical dissection studies in table 5 . Both sitting and supine estimates are included in the calculation of the mean values for the scintigraphic and argorw dilution techniques.

\section{Discussion}

There have been few previous attempts too measure the volume of lobes or segments of the lungs in living man. Menkes et $\mathrm{al}^{4}$ reported the measurement of sublobar lung volume in th dog by two methods. The first was measuring the volume of air flowing from a segment by collateral channels after occlusion of its bronchu@ 
during slow deflation of lobes in isolated and intact dog lungs. The second method was injection of a radio-opaque viscous mixture into a segment which was excised from the isolated lung after drying and its volume measured directly. They found close agreement between the results obtained by these two methods. Horsfield $^{3}$ studied human lungs at postmortem by anatomical dissection and measurement of a bronchial cast, and good agreement exists between his results and those presented in this study particularly when postural differences are taken into account.

The simplest of the methods presented in this paper is that of measuring individual lung and lobar volumes from routine plain chest radiographs. Using a computer to reduce the time required for radiographic lung volume measurements, it is possible to estimate the volume of all lobes from a PA and lateral radiograph in a matter of minutes. All that is required of the patient is to have the two radiographs taken under strictly supervised conditions of known geometry with respect to target-film and patientfilm distances so that accurate magnification factors can be determined.

Although the radiographic method depends on being able to see the interlobar fissures in the lateral radiograph, this is possible in many films taken at TLC. When a knowledge of lobar volumes is important clinically and the radiographic fissures are not clearly visible or are distorted and difficult to distinguish from cyst margins, either of the bronchoscopic methods can be used. Both radiographic and scintigraphic methods also depend upon the assumption that the plane of the interlobar fissures in the lateral radiographic position is in the line of the X-ray beam. The results of the comparison of volume estimates by these methods and those of the argon-dilution technique, which makes no such assumption, suggests that any errors introduced by it are small.

The radiographic method for lung volume estimation used in this study is based on an assessment of the actual cross-sectional shape of the thoracic structures ${ }^{1}$ which applies as well to individual lung and lobar volumes as it does to total lung volume estimation. For the measurement of the volume of cysts however this is not so. Cyst volumes were estimated by assuming them to have the same horizontal cross-sectional area as ellipses generated by their PA and lateral diameters as seen in the radiographs. Once again, the close agreement of these volume estimates with those of other independent physiological methods, as shown in the case histories, suggests that this shape assumption is a reasonable one.

The clinical usefulness of these techniques has been reported elsewhere. Another application of lobar volume estimation is to permit measurement of ventilation, effective perfusion, tissue and water volumes, and diffusing capacity on an absolute basis for each lobe. Values for these indices per unit lung volume have been established in normal subjects at rest and during exercise by the joint studies of Denison et $a^{6}$ and Scheid et $\mathrm{al}^{7}$ using mass spectrometric techniques during bronchoscopy. Lobar volume estimates from chest radiographs taken under the same postural conditions, permit quantitation of these lobar indices as absolute values. The radiographic method is also particularly applicable to the study of the effects of posture on different parts of the lungs. The differences in lobar proportions of TLC shown in these radiographic and gas-dilution studies demonstrates that such postural effects do occur in health and their role in lung disease requires further evaluation. The normal values for individual lung and lobar volumes determined by the methods presented in this paper have been useful as a reference standard for those of patients being investigated for pulmonary disease. These volume estimates should prove useful also in the functional assessment of patients with focal and generalised disorders of the lungs.

These studies were supported by a research grant from the Asthma Research Council of Great Britain, and form part of an MD thesis submitted by RJP to the University of Melbourne.

\section{References}

1 Pierce RJ, Brown DJ, Holmes M, Cumming G, Denison DM. The estimation of lung volume from chest radiographs using shape information. Thorax 1979; 34:726-34.

2 Williams SJ, Pierce RJ, Davies NJH, Denison DM. Methods of studying lobar and segmental function of the lung in man. $\mathrm{Br} J$ Dis Chest 1979; 73:97-112.

3 Horsfield K. Morphology of the human bronchial tree. MD Thesis, University of Birmingham, 1967.

4 Menkes H, Lindsay D, Gamsu G, Wood L, Muir A, Macklem PT. Measurement of sublobar lung volume and collateral flow resistance in dogs. J A ppl Physiol 1973; 35:917-21.

5 Pierce RJ, Davies NJH, Denison DM, Citron KM. A young man with multiple pulmonary cysts. Scand J Respir Dis 1980; in press. 
6 Denison DM, Davies NJH, Meyer M, Pierce RJ, Scheid P. Single-exhalation method for the study of lobar and segmental function in man by mass spectrometry. Respir Physiol 1980; in press.
7 Scheid P, Meyer M, Davies N, Pierce R, Denison DM. A study of lobar ventilation, perfusion and carbon monoxide transfer capacity during rest and exercise in man. Respir Physiol 1980; in press. $\stackrel{\odot}{\circ}$ 